\title{
Mulheres em festas: a vida em movimento na memória de viajantes estrangeiros na Porto Alegre do século XIX
}

\author{
Cleusa Maria Gomes Graebin ${ }^{1}$ \\ Rejane Silva Penna
}

\begin{abstract}
In this paper, the source is the writings of travelers, and the objective, their view of the women in the festivities of the city of Porto Alegre (Rio Grande do Sul) in the XIXth century. The nine travelers investigated integrated a group of Europeans that visited the state of Rio Grande do Sul in the XIXth century. Their texts where analyzed considering the place of the viewer, the purpose of the written report and to whom that report is destined. The condition of foreign did not guaranteed a view capable of exemption and many of the writings where responsible for the construction of stereotypes about women of this State. However, when considering the conditioners of the view, the observations made by the travelers allow us to formulate a less homogeneous idea of the past daily life and to comprehend the complex systems of relations that where formed in the society of Porto Alegre.
\end{abstract}

Key-words: Travelers literature, Women. Festivities, Porto Alegre, Memory

Resumo: Neste trabalho, toma-se como fonte a literatura de viajantes e, como objeto, seus olhares sobre as mulheres nas diferentes festas da cidade de Porto Alegre (Rio Grande do Sul) no século XIX. Os nove viajantes investigados integram conjunto de europeus que visitaram o Rio Grande do Sul no século XIX. Os seus textos foram analisados considerando o lugar de quem olha, para o quê e a quem se destina o relato escrito daquilo que foi captado pelo olhar. A condição de estrangeiro não garantiu um olhar capaz de isenção e muitos dos relatos foram responsáveis pela construção de estereótipos sobre as mulheres sul-riograndenses. No entanto, ao considerar os condicionantes do olhar, as observações dos viajantes permitem

1 Doutora em História (Unisinos). Professora e coordenadora do Programa de Pós-Graduação em Memória Social e Bens Culturais do Unilasalle. Professora do Curso de História do Unilasalle. Coordenadora do Museu e Arquivo Histórico La Salle. Pesquisadora associada ao Arquivo Histórico do Rio Grande do Sul. Pesquisa sobre Patrimônio cultural, festas e celebrações, memória social e história institucional.prcleusa@unilasalle. edu.br; cleusagr@terra.com.br

2 Doutora em História (PUCRS). Historiógrafa do Arquivo Histórico do Rio Grande do Sul. Membro do Grupo de Pesquisa Sociedade, Imigração e Urbanização (PUCRS/CNPq). Pesquisa sobre memória social, história institucional e migrações urbanas. rejanepenna@uol.com.br 
formularmos uma idéia menos homogênea de nossos cotidianos passados e compreendermos os complexos sistemas de relações que se formavam na sociedade portoalegrense.

Palavras-chave: Literatura de viajantes, Mulheres, Festas, Porto Alegre, Memória

Quando alguém faz uma viagem, então tem alguma coisa para contar, diz a voz do povo e imagina o narrador como alguém que vem de longe. (BENJAMIN, 1983, p. 58)

\section{Introdução}

Neste trabalho, toma-se como fonte de estudo, a literatura de viajantes ${ }^{3}$ e, como objeto, seus olhares sobre as mulheres nas diferentes festas da cidade de Porto Alegre (Rio Grande do Sul) no século XIX. Embora vários pesquisadores já tenham proporcionando reflexões aprofundadas, formando um amplo painel sobre a visão dos viajantes estrangeiros em terras brasileiras, a contribuição que se traz é a de incluir elementos que auxiliem a diminuir a imensa lacuna informacional sobre a vida das mulheres no Rio Grande do Sul, nesse caso, num período em que se ampliava a malha urbana. Falamos aqui como historiadoras utilizando literatura como traço que se constitui em fonte histórica, a qual poderá responder à questão que formulamos, ou seja: como os viajantes observaram as mulheres na sociedade porto-alegrense, em muitos aspectos semelhante à européia, porém, indiscutivelmente, sul-americana? Acrescenta-se a essa pergunta, outras, visando a observar o próprio observador e seus filtros: Quem é o viajante e de onde vem? De qual lugar e para quem fala? Qual o seu universo cultural em termos de crenças pessoais, conhecimentos políticos, científicos e filosóficos?

Das tantas possibilidades que as narrativas de viagens oferecem, pretende-se apreender o que dizem os viajantes sobre as mulheres em movimento, ou seja, nas modalidades festivas, no espaço da vida coletiva.

Segundo a historiadora Miriam Moreira Leite (apud MICHELIN, 2005), os relatos de viagens, uma das formas mais antigas de literatura, deram origem a reflexões sobre as diferenças existentes nas sociedades humanas, sendo algo intermediário entre o documento pessoal (diário íntimo e correspondência) e o relatório oficial (memória descritiva com objetivos políticos, econômicos e educacionais). Aliás, grande parte dos relatos, integrais ou parciais, publicados, dos viajantes ou estrangeiros que em geral escreveram sobre o Brasil, foi disponibilizada, inicialmente, não em livros, mas em publicações periódicas da mais variada natureza.

Para se ter uma idéia da extensão dessa literatura, verifica-se, atualmente, que ela aparece em livros volumosos, compostos de cinco ou mais tomos, em livros curtos, que não ultrapassaram duzentas páginas, em artigos de revistas e em manuscritos. Registra-se ainda sob a forma de literatura para adultos e crianças, romance de aventuras, literatura fantástica ou romance epistolar, havendo na segunda metade do século XIX, reportagens jornalísticas e guias turísticos (LEITE, op. cit).

3 "A influência dos relatos de viagem de estrangeiros na constituição do imaginário sobre o Brasil adquire sua devida proporção se pensarmos que até meados do século XIX eles permanecem como uma das poucas fontes de conhecimento sobre o país" (BATISTA, 2009, p. 122). 
Infelizmente, vários desses escritos permanecem quase que intocados pelo olhar do historiador, fato observado por Matos, o qual afirma que se é verdade que muitos desses relatos vieram, com o tempo, a ser publicados em livros, facilitando, portanto, a consulta, não é menos verdade que a grande maioria permanece 'escondida' nas páginas das publicações periódicas que os abrigaram” (1988, p. 267). Enumera que dentre estas publicações constam a Revista do Instituto Histórico e Geográfico Brasileiro, as revistas dos diversos Institutos Históricos e Geográficos estaduais, os Anais da Biblioteca Nacional, o Anuário do Museu Imperial, a Revista do Patrimônio Histórico e Artístico Nacional, além de diversas revistas de museus, boletins, entre outros.

Alguns relatos foram publicados integralmente, como "Viagem ao interior do Brasil", de Freireyss e o relato da viagem a São Paulo, do sueco Gustavo Beyer (Revista do Instituto Histórico e Geográfico de São Paulo, vols. 11 e 12, respectivamente), as "Impressões de um jovem diplomata no Brasil”, de Henri Allizé (Revista Brasileira, vol.3, $4^{\mathrm{a}}$ fase), os relatos integrais publicados em capítulos, como a narrativa da viagem do inglês Bigg-Wither ao Paraná, ao longo de vinte e três números da revista "Eu sei tudo" e os relatos parciais, como as "Cartas sobre a Bahia", da inglesa Mrs. Kindersley, publicadas no tomo primeiro dos Anais do Museu Paulista. Também importante contribuição foi a obra do médico italiano Alfonso Lommonaco, "Al Brasile", publicada em Milão, no ano de 1889 , a respeito de sua visita ao Brasil de 1885, contendo muitas informações e depoimentos dos costumes de então.

A visão dos viajantes europeus sobre as cidades do Brasil deve ser inserida em um contexto observado por Duarte (2002), ao analisar que no decorrer do século XIX assistia-se a um crescente otimismo dos europeus em relação a si próprios e à cultura da qual participavam, na qual a evolução, progresso, produção e civilização eram motivos de orgulho a ponto da incompreensão e intolerância de qualquer outra sociedade em que os homens pudessem viver diferentemente.

Mary Louise Pratt, (2000) refletindo sobre as narrativas de viajantes do período colonial, analisava-as como experiência individual do sujeito-viajante às portas da modernidade, em que a viagem para terras longínquas surgia claramente como metáfora da viagem interior, suportando experiências pioneiras de subjetividade e autoconhecimento. Em um discurso auto-reflexivo, o homem ao viajar, observava, refletia e catalogava terras estranhas e povos selvagens, realizando com a viagem uma apropriação discursiva das terras estrangeiras, dando origem a uma configuração nova, porém extremamente efetiva de conquista, que a autora denominou de "anti-conquista", em alusão ao caráter aparentemente pacífico e reflexivo do viajante-naturalista e às características abstratas da apropriação catalogadora por ele promovida.

A observação de Peter Burke (2000) de que os relatos revelam, ao mesmo tempo, a percepção da distância cultural e a tentativa de se chegar a um acordo ou 'traduzi-la' em algo mais conhecido, porque à medida que críticas são feitas aos povos visitados, buscase sempre a comparação com o padrão cultural do narrador, completa a perspectiva sob a qual se aborda o olhar do viajante sobre as mulheres em festas nas cidades do Rio Grande do Sul, durante o século XIX.

Ao longo dos tempos, historiograficamente, no Rio Grande do Sul, foi dada ênfase a determinados elementos que se constituíram como suportes de construção social de identidade, constantemente atualizada, reposta e evocada. ${ }^{4} \mathrm{O}$ homem sul-riograndense

4 Gutfreind (1992, p. 48-52) explica a construção historiográfica do passado heróico e mitificação do Rio Grande do Sul, assim como a do gaúcho como tipo social. 


\section{Conexão Letras}

foi representado como importante tipo social em longo processo de elaboração cultural, transformando-se em símbolo de identidade regional: o gaúcho, o cavaleiro e o peão de estância, cuja existência seria marcada pela liberdade da vida levada nos pampas, a presença do cavalo, a lealdade e honra, a virilidade e bravura do homem ao enfrentar seu inimigo ou mesmo as forças da natureza, ausente do lar em virtude das guerras. As mulheres, obscurecidas pela presença de seus homens, foram vistas como santas, abnegadas, trabalhadoras, e como suportes dos chamados "troncos seculares" formadores das famílias que originaram as elites sul-riograndenses. "Santas Mães", "esposas daqueles augustos varões que são os patriarcas das nossas famílias", assim foram denominadas por João Borges Fortes (1998).

Franzen (2004) cita algumas obras portuguesas de cunho moralista como "Espelho de Casados" (1540), de João de Barros, "Casamento Perfeito" (1630), de Diogo de Paiva Andrade e "Carta do Guia de Casados" (1651), de Francisco Manoel de Melo, as quais traziam conselhos quanto ao relacionamento entre maridos e esposas. Essas obras recomendavam: nada de ócio...estar ocupada com o trabalho...obedecer ao marido sem perguntar o porquê das coisas...mesa bem posta...dar de comer ao marido... Franzen infere que as mulheres de origem luso-açoriana que vieram para o Rio Grande do Sul, certamente haviam sido educadas segundo esses preceitos. A historiografia de cunho tradicional encarregou-se de exaltá-los, servindo os mesmos como suportes para as representações construídas sobre as mulheres sul-riograndenses.

$\mathrm{Na}$ área da História, as mulheres foram alçadas à condição de objeto e sujeito com as transformações da historiografia ${ }^{5}$ e a explosão do feminismo ${ }^{6}$. A partir da década de 1970, com a emergência da História das Mulheres, historiadores, partindo de diferentes abordagens, começaram a se debruçar sobre o universo feminino ${ }^{7}$, articulando diferentes áreas do saber como história, antropologia e sociologia.

No mundo acadêmico, foram criados grupos e linhas de pesquisa, abrigando pesquisadores das mais diversas áreas do conhecimento que se associaram para tratar temas que levassem em conta, questões existenciais das mulheres em sintonia com os interesses dos movimentos feministas formais e informais. Mesmo pesquisadores não engajados nos movimentos (alguns críticos dos mesmos), os temas sobre os quais pesquisavam acabaram por colocá-los a seu serviço.

5 “.... infância, a morte, a loucura, o clima, os odores, a sujeira e a limpeza, os gestos, o corpo [...], a feminilidade" passaram a ser vistas como possíveis objetos da história e as mulheres encaradas como sendo também sujeitos da história. BURKE, Peter. A escrita da História: novas perspectivas. SP: UNESP, 1992, p. 11.

60 movimento feminista, em suas várias vertentes, provocou um profundo questionamento sobre o lugar e a função social das mulheres. No Brasil, o movimento feminista existe desde os tempos do império mas é na década de 1970 — durante o contexto da luta pela anistia — que sua presença na esfera pública é mais significativa. Nos anos 1980 crescem os movimentos pelo país e algumas vertentes passam a defender que mulheres e homens são diferentes mas não desiguais. Nos anos 1990 os debates sobre o movimento feminista e sobre o conceito de gênero são aprofundados a partir de reflexões, análises e debates promovidos pelo mundo acadêmico.

7 No âmbito acadêmico brasileiro, os estudos sobre as mulheres ocuparam grande espaço da década de 1970, tiveram seu apogeu na década de 1980, quando o tema alcançou maior evidência. Num primeiro momento (1980/85), os estudos estiveram mais voltados à mulher e sua participação e representação política nas esferas macro do poder. Nos anos seguintes (1985/87), a pesquisa voltou-se mais para a mulher enquanto sujeito e sua identidade no cotidiano. No final da década de 1980 (1987/89) deu-se a incorporação do feminino e masculino e o início da incorporação da categoria de gênero. A partir da legitimação do tema, núcleos de estudo foram organizados nas Universidades sobre Relações Sociais de Gênero, como o NEMGE na USP, "Pagu" na Unicamp (Campinas, SP), entre outros. BANDEIRA, Lourdes Maria; OLIVEIRA, Eleonora M. Trajetória da produção acadêmica sobre as relações de gênero no grupo de trabalho Mulher e política. In: Ciências Sociais, hoje, São Paulo: ANPOCS/Vértice, 1991. 
A renovação historiográfica foi acompanhada da inclusão, como fontes históricas, de diferentes vestígios da existência humana. A produção de fontes orais, por exemplo, auxiliou na reconstrução de memórias e registros sobre vidas de mulheres.

Nas décadas finais do século XX, antigos temas foram revisitados, surgiram debates conceituais sobre gênero ${ }^{8}$ que buscavam resolver contradições e impasses postos entre os pesquisadores(as) sobre o conceito e entre estes(as), os movimentos feministas e ONGs a seu serviço, o que redundou na construção de novos saberes.

Ao refletir sobre estas questões, Costa (2003) constatou que o conceito de gênero, nas últimas décadas do século XX, moveu-se em circunstâncias de crescimento do movimento para o empoderamento das mulheres em diversos campos, na emergência de novos padrões de sociabilidade feminina, na mudança do estado de consciência que homens e mulheres estão tendo sobre si e sobre o mundo que os cerca, o que os leva a perceber a sua humanidade e responsabilidade social em comum.

No Brasil, os anos 1990 foram férteis em termos de publicações, estudos sobre o conceito de gênero, já em debate nas décadas anteriores, como também sobre a história das mulheres. Destacam-se Uma questão de gênero, obra de 1992, publicada pela Fundação Carlos Chagas, trazendo inúmeros artigos decorrentes de estudos de brasileiras que partiam de diferentes posicionamentos em relação ao conceito. Mary Del Priori publicou, em 1997, História das Mulheres no Brasil. Na apresentação da obra, a autora afirma que "a história das mulheres não é só delas, é também aquela da família, da criança, do trabalho, da mídia, da leitura. É a história do seu corpo, da sua sexualidade, da violência que sofreram e que praticaram, da sua loucura, dos seus amores e dos seus sentimentos." Os Cadernos Pagu de 1994 e 1995, também trouxeram contribuições para as discussões com artigos sobre o conceito de gênero e também estudos sobre mulheres que não recorriam à noção de gênero. ${ }^{9}$

\section{Estudos historiográficos sobre mulheres sul-riograndenses a partir da literatura de viajantes}

Tratar de temas relativos às experiências das mulheres no Rio Grande do Sul é algo um tanto novo, mas que, aos poucos, vem tomando lugar a partir de investigações realizadas em diferentes áreas do saber. Consultando o acervo de Teses e Dissertações de Programas de Pós-Graduação em História de Universidades sediadas no Estado é possível, sem pretensão de cartografar exaustivamente a produção de estudos que englobam o conceito de gênero e/ou história das mulheres, uma visão quantitativa dos mesmos.

8 “'A partir da década de 1970, 'gênero' tem sido o termo usado para teorizar a questão da diferença sexual. Foi inicialmente utilizado pelas feministas americanas, sendo inúmeras as suas contribuições. A ênfase no caráter fundamentalmente social, cultural das distinções baseadas no sexo, afastando o fantasma da naturalização; a precisão emprestada à idéia de assimetria e de hierarquia nas relações entre homens e mulheres, incorporando a dimensão das relações de poder; o relevo ao aspecto relacional entre as mulheres e os homens, ou seja, de que nenhuma compreensão de qualquer um dos dois poderia existir através de um estudo que os considerasse totalmente em separado, constituem-se em algumas dessas contribuições. Acresce-se a significação, emprestada por esses estudos, à articulação do gênero com a classe e a raça/etnia. Interesse indicativo não apenas do compromisso com a inclusão da fala dos oprimidos, como da convicção de que as desigualdades de poder se organizam, no mínimo, conforme estes três eixos." SOIHET, Rachel História das mulheres e relações de gênero: debatendo algumas questões. Disponível em: http://www.comciencia.br/reportagens/mulheres/16.shtml , acessado em 12/12/2006.

9 Sobre a constituição do campo historiográfico da História das Mulheres e das Relações de Gênero, ver SOIHET, Rachel; PEDRO, Joana Maria. A emergência da pesquisa da História das Mulheres e das Reações de Gênero. In: Revista Brasileira de História. São Paulo, v. 27, nº 54, p. 281-300, 2007. 


\begin{tabular}{|c|c|c|}
\hline PERIODO & INSTITUIÇÃO & $\begin{array}{c}\text { NÚMERO DE TRABALHOS (TESES } \\
+ \text { DISSERTACÇOES) }\end{array}$ \\
\hline $1993-2010$ (JUNHO) & PUCRS & 20 \\
\hline $1990-2009$ & UNISINOS & 13 \\
\hline $1999-2010($ JUNHO) & UERGS & 8 \\
\hline
\end{tabular}

Quadro Produção acadêmica sobre temas voltados para a noção de gênero e ou história das mulheres ${ }^{I 0}$

Refinando a busca de trabalhos de estudos históricos sobre mulheres (em parte ou no seu todo) no Rio Grande do Sul, utilizando, entre as fontes, literatura de viajantes, encontraram-se os textos de: Reichel (2000), Franzen (2004) e Azambuja (2006).

Reichel, no artigo A mulher rio-platense na visão dos viajantes: um sujeito histórico, trata da participação feminina na sociedade platina a fim de identificá-la como sujeito histórico. Dois viajantes, Felix de Azara e Alejandro Malaspina contribuíram para a criação por parte da historiografia dita tradicional, vinculados a um projeto liberal e modernizador, de estereótipo de mulher de vida livre, denominada por "china", ou então de mulher dolente, passiva e relegada à esfera doméstica. O gaúcho "livre como o vento" e "a china" representariam o estágio de "barbárie" da sociedade platina. Ao trabalhar com a literatura de viajantes do século XIX, Reichel constata outras versões sobre a atuação das mulheres em diferentes espaços (mundo urbano e rural) e formas. Tanto poderiam estar ligadas às atividades domésticas como vinculadas aos trabalhos na agricultura e pecuária, à tecelagem, costura, cozinha, comercialização de alimentos pelas ruas das cidades, em balcões de lojas e "vendas". A autora conclui que a partir das narrativas de viajantes do século XIX, a mulher adquire visibilidade e atua como sujeito histórico na região platina.

Franzen, em Mulheres açorianas na formação do Rio Grande do Sul, utiliza entre as fontes arroladas para essa pesquisa, literatura de viajantes (militares, comerciantes, naturalistas) que percorreram o Rio Grande do Sul entre 1750 e 1822. Afirma que são raros e contraditórios os relatos sobre as mulheres. No entanto, aparece uma constante, também apontada por Reichel: os viajantes elaboram para as mulheres que viviam no espaço rural, representações diferenciadas para mulheres do espaço urbano. No campo, mulheres "grosseiras", dedicadas às lides domésticas que se escondem ou são escondidas pelos seus homens das vistas de estranhos; nas cidades (Rio Grande e Porto Alegre), mulheres que frequentavam saraus, bailes, sendo menos acanhadas, mais falantes e "vestindo com decência". A autora reconhece que muito há, ainda, a pesquisar, utilizando a potencialidade da literatura de viajantes como fonte.

Azambuja, na dissertação Os dois lados da janela: o público e o privado das mulheres porto-alegrenses entre 1774 e 1887, através dos processos de divórcio, utiliza sete relatos de viajantes que passaram por Porto Alegre durante o século XIX, buscando nessas narrativas, descrições sobre a presença das mulheres, sua importância na sociedade e sua inserção no contexto familiar para após, partindo do estudo dos processos de divórcio desvelar o espaço privado de mulheres porto-alegrenses.

A exigüidade do número de trabalhos sobre mulheres, utilizando literatura de viajantes como fonte histórica pelos historiadores, sinaliza para a relevância do estudo que ora apresentamos.Utilizamos para este trabalho, textos (alguns em primeira versão em língua portuguesa) reunidos por Noal Filho e Franco (2004).

10 Fontes:

http://www.unisinos.br/ppg/historia

http://www.ufrgs.br/ppghist/teses.asp

http://www.ufrgs.br/ppghist/dissertacoes.asp

http://www3.pucrs.br/portal/page/portal/ffchppg/ppgh/ppghTesesDissertacoes 


\section{Os viajantes e condicionantes do olhar}

Porto Alegre, capital do Rio Grande do Sul (no século XIX denominado Província de São Pedro), situada no ponto mais meridional do Brasil, despertou o interesse de diversos viajantes europeus. Como afirma Burke, "o ingresso em uma cultura estranha ou semi-estranha transforma o viajante em espectador, observador se não em voyeur (2000, p. 142-143). Seu olhar sobre a cidade é perpassado pelo desejo de educar e proporcionar momentos de lazer aos seus leitores, bem como, está vinculado ao contexto político, econômico, social de sua época e à corrente de pensamento a que está vinculado. ${ }^{11}$

Os viajantes aqui citados integram conjunto de europeus que visitaram o Rio Grande do Sul no século XIX, que se constituía em "espaço de trânsito para os países platinos e andinos, pólo de atração para imigrantes europeus, [comerciantes e naturalistas] e área de deslocamento de militares, funcionários em serviço [missionários e clérigos]" (NOAL FILHO; FRANCO, 2004 a, p. 7).

Cabe-nos, agora, apresentar os viajantes:

\begin{tabular}{|c|c|c|c|c|c|}
\hline Nome & $\begin{array}{c}\text { Ano de } \\
\text { nascimento }\end{array}$ & $\begin{array}{c}\text { Local de nasci- } \\
\text { mento }\end{array}$ & Atividade & $\begin{array}{c}\text { Período } \\
\text { de visita } \\
\text { a Porto } \\
\text { Alegre }\end{array}$ & $\begin{array}{c}\text { Obra na qual se refere às } \\
\text { mulheres em Porto Alegre }\end{array}$ \\
\hline $\begin{array}{c}\text { Auguste de Saint- } \\
\text { Hilaire }\end{array}$ & 1779 & Orleans (França) & $\begin{array}{c}\text { Cientista-Natu- } \\
\text { ralista }\end{array}$ & $\begin{array}{c}1820- \\
1821\end{array}$ & Viagem ao Rio Grande do Sul. \\
\hline $\begin{array}{c}\text { Heinrich Trächsler } \\
\text { Arsène Isabelle }\end{array}$ & 1811 & $\begin{array}{c}\text { Zürich-Predgerrn } \\
\text { (Suíça) }\end{array}$ & $\begin{array}{c}\text { Militar-merce- } \\
\text { nário }\end{array}$ & 1828 & $\begin{array}{c}\text { Viagens, vicissitudes e } \\
\text { aventuras tragicômicas de } \\
\text { um suíço... }\end{array}$ \\
\hline Joseph Hörmeyer & 1824 & Havre (França) & $\begin{array}{c}\text { Comerciante- } \\
\text { naturalista }\end{array}$ & 1834 & $\begin{array}{c}\text { Viagem ao Rio da Prata e ao } \\
\text { Rio Grande do Sul. }\end{array}$ \\
\hline Marie Van Langen- \\
donck
\end{tabular}

* Brummer foi a denominação dada a soldados mercenários vindos do Schleswig-Holstein, pequenos Estados incorporados à Prussia entre 1848-1851. 0s mercenários foram contratados pelo governo imperial brasileiro para a campanha do Brasil contra Oribe e Rosas em 1851. Ver: WIEDERSPAHN, Henrique Oscar. Das guerras Cisplatinas às guerras contra Rosas e contra o Paraguai. In: Enciclopédia Rio-grandense. Canoas: Editora Regional, 1956.

\section{Quadro Dados biográficos sobre os viajantes ${ }^{12}$}

Ao observarmos o quadro com síntese biográfica dos viajantes, podemos perceber diferentes razões dos mesmos para se afastarem dos seus espaços de origem: interesses científicos; busca de propriedade de terras; fuga de perseguição política; serviço diplomático;

11 Sobre descrições e classificações de cidades, ver Lepetit, 2001.

12 Fonte: NOAL FILHO; FRANCO a e b, 2004. 


\section{Conexão Letras}

atividades mercenárias; atividades educativas, médicas e ou jornalísticas. O forasteiro olha para os lugares e culturas que se lhe apresentam a partir de si mesmo, seu universo cultural, seu mundo com seus valores. Nesse sentido, "[...] viagens são sempre empreitadas no tempo" (CARDOSO, 1989, p. 358). A viagem está relacionada com a atividade de "olhar", deliberada e intencional, remetendo a tudo o que já foi visto, experenciado e sentido. Portanto, carregada de valores que adjetivam o "outro" em relação ao "eu” (CARDOSO, 1989).

$\mathrm{O}$ viajante olha e relata a partir daquilo que carrega consigo e na memória coletiva ${ }^{13}$ que o acompanha. Dá-se a experiência do estranhamento, fora do seu lugar, mas enraizado neste - condicionante do olhar —, traça a diferença, a alteridade e, portanto, comparações. Assim, o "olhar-viajante" se estabelece a partir da visão de mundo de quem olha. É preciso, portanto, considerar o lugar de quem olha, para o quê e a quem se destina o relato escrito daquilo que foi captado pelo olhar.

As formas de narrar são construções que se apóiam em metodologias específicas (ver, anotar, descrever) dos naturalistas, médicos, juristas e etnólogos; nos formatos dos diários de viagens, gênero literário bastante apreciado na Europa do século XIX; nos relatórios de diplomatas; e em cartas para as quais havia manuais que orientavam como escrevê-las. Alguns dos relatos foram escritos no momento que o viajante observava e registrava sua experiência, descrevendo as dificuldades e autosuperação: "Escrevi estas páginas debaixo de árvores, em choças, entre europeus, negros, índios e mestiços, às vezes em cômoda situação de vida, às vezes constrangido às mais duras privações, sem teto, sem cama, sem comida e sem bebida". (AVÉ-LALLEMANT, 1980, p. 17). Outros relatos foram escritos após o retorno dos viajantes para a Europa e nesse caso, a memória recriaria experiências vividas e cenários.

\section{Olhando o outro: mulheres em festas na Porto Alegre do século XIX}

Os viajantes, quaisquer fossem suas atividades ou motivações para que estivessem em Porto Alegre, durante o século XIX, olharam modos de ser, hábitos, comportamentos, culinária e cotidiano dos habitantes da cidade. Eram condicionados pelo que Elias (1990) expressa como processo civilizador, fundamentado em ideias iluministas mescladas com educação a partir de pressupostos moralistas cristãos. Assim, os viajantes construíram representações sobre aquilo que era observado, as quais foram narradas nos seus escritos.

Guardados os cuidados para trabalhar com essas fontes, como cita Soihet:

[...] a literatura deixada por esses viajantes constitui-se numa documentação ímpar para os historiadores e historiadoras preocupados com o cotidiano das pessoas comuns e com suas manifestações culturais. Nesse sentido, embora atravessados por seus preconceitos, os relatos e iconografias deixados por esses viajantes nos permitem o acesso a um universo, via de regra, caracterizado por sua opacidade nos estudos históricos tradicionais - aquele da festa ... (2000, p. 92)

Mulheres em festas ${ }^{14}$ na Porto Alegre oitocentista — o que viram (ou não viram) os viajantes? Exótico, selvagem, sensual, luxúria, desordem, inusitado são suas repre-

13 Sobre memória coletiva ver: HALBWACHS, Maurice. A memória coletiva. São Paulo: Vértice, 1990.

14 Tratamos aqui com a concepção da festa como "vida em movimento", tendo em vista, não só essa opor-se ao ritmo regular da vida rotineira, instaurando novas temporalidades, como, a partir das atualizações que são suscitadas a cada edição, podermos ver o humano em sua criação. Ainda, ao aglutinar cotidianos dispersos, a festa é espaço de diversas figurações sociais. Assim, ocorrem diferentes festas dentro da festa (DA MATTA, 1980; DEL PRIORE, 1994; DURKHEIM, E. 2000; DUVIGNAND, J., 1973; ITANI,, 2003; ISAMBERT, 1982; MORAES FILHO, 1999; THOMPSON, E. P., 1998). 
sentações, mas sabe-se que "os europeus usavam suas estruturas intelectuais e organizacionais convencionais, moldadas durante séculos de contatos indiretos com outras culturas, e que essas estruturas impediam em grande parte, percepção clara da radical alteridade das terras e povos americanos" (GREEMBLATT, 1996, p. 78).

\subsection{Festas privadas}

Era costume entre as famílias abastadas de Porto Alegre realizarem, com freqüência, festas privadas em suas residências. Em alguns momentos, os próprios viajantes eram o objeto da festa a qual poderia constituir-se de baile, jantar ou sarau.

Uma descrição nos é dada por Auguste de Saint-Hilaire relatando ter sido convidado por um francês, representante de casa comercial do Rio de Janeiro, para um baile realizado na tarde de 12 de julho de 1820 .

Sabendo que essa casa era uma das mais recomendáveis de Porto Alegre não hesitei em aceitar o convite. Deparei, então, em um salão bem mobiliado e forrado de papel francês, uma reunião de trinta a quarenta pessoas, homens e mulheres. Como se tratavam de parentes e amigos íntimos não havia luxo nos trajes. As mulheres vestiam-se com simplicidade e decência. [...] Dançaram-se valsas, contradanças e bailados espanhóis. Algumas senhoras tocaram piano, outras cantaram com muita arte, acompanhadas ao bandolim, e a festa terminou entre pequenos jogos de salão. [...] As senhoras falam desembaraçadamente com os homens e estes cercam-nas de gentilezas. [...] Ainda não tinha visto no Brasil uma reunião semelhante. No interior, como já repeti uma centena de vezes, as mulheres se escondem e não passam de primeiras escravas da casa [...]. Entre as mulheres que vi em casa do Sr. Patrício havia algumas bonitas. Na maior parte eram muito brancas de cabelos castanhos escuros e olhos pretos. Algumas graciosas, porém sem aquela vivacidade que caracteriza as francesas. (SAINT-HILAIRE, apud FRANCO; NOAL, 2004, p. 41)

Ao observar as mulheres e seu comportamento, o faz, a partir de um parâmetro: as mulheres francesas. A partir desse condicionante, seu relato é marcado por comentários sobre moralidades, vestuário, costumes e hábitos. Emerge, também, da sua narrativa, a preocupação de mostrar as diferenças no tratamento dado às mulheres da cidade e do "interior", traçando comparações com o que observara no meio rural, em outras províncias brasileiras e localidades do Rio Grande do Sul. Também, pontua elementos cênicos como a música, as danças e os jogos de salão.

Outro viajante a testemunhar festa privada foi Heinrich Trächsler, o qual chegou a Porto Alegre em 1828. Demorou-se pouco na cidade, observando, no entanto, a quase inexistência de escolas e a segregação da mulher, situações para as quais teceu duras críticas. Em rápido e cortante comentário, faz observações desabonadoras ao comportamento feminino em eventos sociais:

.. em vão procura-se nas feições judias dos homens ou dos rostos, por vezes bonitos de suas mulheres e filhas conseguir perscrutar o estado de suas almas; rombudas almas enlameadas, voluptuosidade vulgar, em sua ignorância[...] Os verdadeiros e puros prazeres da vida social são desconhecidos por estes "Chineses" $"$; não compreendo o deplorável blá-blá-blá ${ }^{16}$ das reuniões femininas de bisbilhotice - cujas características, algumas

15 A expressão "chineses", utilizada pelo viajante significa pessoas exóticas, desconhecidas e distantes geográfica e culturalmente do mundo europeu. (N.T.) (p. 62)

16 Fofocas de aldeia (N.T.) (p. 62) 
vezes também podem ser atribuídas a grupos masculinos - que não conhecem melhor entretenimento do que tratar da quantidade de suas panelas, da situação doméstica do vizinho, da qualidade de seu cãozinho... (apud FRANCO; NOAL, 2004, p.62)

Trächsler olha para as mulheres a partir de contexto existencial marcado por valores e modelos europeus, evidenciando experiência de estranhamento que Greenblatt explica como "choque da diferença cultural extrema" (1996, p. 78). Compreende-se, assim, a emissão de juízos e julgamentos sobre o que via, partindo de conceitos de civilização e modernidade presentes no cenário europeu.

Arsènne Isabelle, ao visitar Porto Alegre, em 1834, de igual modo, chamava a atenção para a quase inexistência de escolas e para o fato de as mulheres serem mantidas por seus pais e maridos trancadas em casa. Quando saiam da reclusão familiar para freqüentar uma festa privada, seu traje

...é um vestido de cetim branco, bordado e palhetado de ouro e prata, sapatos e
luvas de cetim e muitas jóias. Os cabelos são enfeitados de flores artificiais. [...]
São, sobretudo, as modas européias, de há seis anos atrás, que fazem sucesso no
Brasil. Vi esses enormes chapéus de palha e tafetá, sobrecarregado de laços de fitas;
abrigos escoceses, vestidos vermelhos e outras monstruosidades semelhantes (apud
FRANCO; NOAL, 2004, p. 72).

Mesmo que a moda estivesse defasada, para o olhar europeu, o fato das mulheres exibirem os melhores vestidos, jóias e muitos adereços, exaltava posição e poder das suas famílias em meio ao grupo social a que pertenciam e confrontavam-se prestígio e rivalidades (DEL PRIORI, 1994, p. 37).

\subsection{Festas religiosas}

Existem diferentes festas religiosas e formas de participar das mesmas, bem como nem sempre é visível a fronteira entre diversão e devoção no campo do sagrado. A festa, seja ela religiosa ou profana, é espaço de sociabilidades, de inclusão social, de partilhamento, de reunião de pessoas diferentes (sem significar que estão unidas), de hierarquias, de passagens, conflitos, trocas e diferenças. Na vida social, alcança diferentes significados para indivíduos e grupos que dela participam.

Joseph Hörmeyer esteve em Porto Alegre em 1851, descrevendo as festas do sábado de Aleluia, quando ocorria a Queima do Judas. Nas residências da Rua da Praia: "[...] encantadores rostos das mulheres e moças, já de per si pouco visíveis, as quais, comparáveis a uma verdadeira mostra de beleza, enfeitam todas as janelas e os balcões." (apud FRANCO; NOAL, 2004, p. 95). Da mesma maneira que outros viajantes, Hörmeyer comenta sobre a reclusão de mulheres das famílias das elites a sua exposição em determinados momentos de celebração coletiva. Relata que estas celebravam postadas nas janelas das casas, sem participarem dos festejos nas ruas.

Marie Van Langendonck, em 1860, quando visitava em Porto Alegre, participou das festividades e celebrações da Semana Santa. Ao descrever o comportamento das mulheres, percebe-se a dificuldade da narradora em conciliar a imagem que trazia na lembrança e aquela que se lhe apresentava.

Na Quinta-feira Santa - enquanto na Europa, nas igrejas [...] vêem-se os fiéis [...] rezar recolhidamente na penumbra em que se deixa a igreja, vestidos modestamente [...] no Brasil as igrejas estão em festa nesse dia [...] As senhoras em roupas resplendentes 
chamam a atenção pelo decote do vestido que descobre os ombros. Os braços nus e a cabeça descoberta, parecem estar prontas para o baile. Elas sentam-se no chão apesar de estarem suntuosamente vestidas. Algumas se sentam sobre os degraus do altar, virando as costas ao Tabernáculo; aí elas conversam, riem, comem doces e certamente nenhuma pensa na solenidade do dia, a qual não chega a ser por elas compreendida. Para ela, a igreja é neste dia, um lugar de reunião onde se encontram os conhecidos, onde se mostra um vestido de seda novo e onde se combina como se rever nas procissões de Sexta-feira Santa e na Ressurreição. (Apud FRANCO; NOAL, 1994, p. 105-106)

Infere-se que era difícil, para a viajante, compreender que existiam formas diferentes de se viver a religiosidade e de participar das celebrações. Essas poderiam ser formas de espetáculo com dimensão estética por meio de alegorias e performances. Nelas, o celebrante via e se dava a ver. Era espaço da devoção e do lúdico, lugar de sociabilidades, de encontro, de subversão e de trocas. Langendonck via a diferença recusando-a. A partir de entendimento de evolução do gênero humano, considerava: "Será que os brasileiros com a simplicidade própria da infância, têm horror a emoções tristes?" (p. 106). Para as mulheres, esses momentos se constituíam como espaços para circularem um pouco mais livremente.

Como comenta Martins (2006), tanto as festas religiosas como as profanas eram tempos de excesso, oportunidade de realizar desordens e brincadeiras por conta do momento festivo.

\subsection{Festas civis}

As festas civis são festas do poder instituídas pelas autoridades e fixadas em calendário próprio. Havia as cerimônias nas ruas, das quais participavam os diversos segmentos sociais, mas em espaços demarcados, e grande parte das comemorações era realizada em locais fechados abrigando as elites locais. Constituíam-se como espetáculos destinados a educar o povo, marcar hierarquias, como estratégias políticas, tanto de legitimação de poder, como de criação de valores. Tomavam as ruas e poderiam ser celebradas por dias, com alguns elementos como os fogos de artifício, a música e a decoração de ruas e residências. De alguma maneira, auxiliavam a dar certo sentido de identidade nacional.

Hugo Zöller esteve em Porto Alegre cerca de 1880 e participou da festa em comemoração à independência do Brasil.

Nessa ocasião reparei no mau jeito de andar da maioria das brasileiras; não poderia ser de outra forma, pois geralmente ficam sentadas em casa, bastante inativas, ou olham pela janela. Elas aparecem relativamente pouco em público e conseqüentemente são muito menos vivas que as espanholas e as francesas. Quando se vê uma dama muito coquete, uma dama com comportamento liberado ou uma dessas que conscientemente se deixam cortejar - e dessas havia alguns exemplares interessantes no baile [...] então se pode deduzir com bastante certeza que ela vem de Montevidéu ou Buenos Aires. (Apud FRANCO; NOAL, 1994, p. 201)

Zöller julga o modo de ser das mulheres, tendo como parâmetro as de Montevideu, Buenos Aires e França. O costume das portoalegrenses de serem contidas, fruto de normas sociais rígidas, conflitava com as perspectivas européias para as mulheres, no final do século XIX. Os relatos configuram o cenário observado pelos viajantes. Esses buscam tornar o que vêem legível, tanto para si mesmos, quanto para os prováveis leitores das suas narrativas. É o olhar do estranhamento que desconhece o que vê e que interroga. O 
padrão de civilidade pelo qual se guiam para o mundo que se lhes apresenta é aquele da Europa oitocentista ${ }^{17}$.

Herrmann Meyer descreve em 1898 as ruas de Porto Alegre em festa, apontando mulheres que compartilham um mesmo cenário, mas com participações diferenciadas.

\begin{abstract}
Hoje, à véspera da maior festa nacional brasileira, o Quinze de Novembro [...] está tudo na mais absoluta desordem; não se consegue chegar em nenhuma repartição pública, as ruas estão decoradas com milhares de bandeiras, enfeitados e vistosos arcos do triunfo e lâmpadas de iluminação, uma banda de música atrás de outra [...] negras velhas - últimas representantes da colônia africana - antigas escravas, com seus lenços vermelhos e turbantes cobrindo cabeças de um grisalho cuja alvura só se encontra nestes "negros da idade da pedra" oferecem guloseimas de origem duvidosa nas esquinas das ruas;[...]; damas em elegantes toillettes (genuínos trajes de passeios são desconhecidos por aqui), com enormes chapéus de penachos e leques, acotovelam-se no trottoir, indiferentes à correria e aos foguetes que explodem sobre, e por vezes, entre a multidão. [...] No dia seguinte [ 16 de novembro] ocorreu o baile festivo do Clube de Remo Porto alegre nas dependências da Sociedade Germânia. [...] Desconcertou-me o curioso costume de que antes da Polonaise quase todas as damas presentes mantinham-se sentadas em apertadas fileiras ao longo das paredes do salão, as mais velhas á esquerda, as mais jovens à direita, cautelosamente afastadas do mundo dos homens que, na ante-sala, espreitavam juntos pelo momento do sinal que lhes permitisse dançar, lançando-se sobre uma das damas previamente escolhidas; após o que, o baile transcorria como um dos nossos (Apud FRANCO; NOAL, 1994(b), p. 54-55).
\end{abstract}

Para o olhar estrangeiro o cenário era de caos e a sensação de desordem estava associada ao intenso movimento e à celebração nas ruas. Os comentários sobre as mulheres negras e as damas elegantes mostram o profundo distanciamento entre os dois grupos. As negras não eram protagonistas das festas, participavam delas a partir do seu trabalho. Meyer descreve seus arranjos de cabeça, seus alvos cabelos e põe sob suspeição a qualidade dos alimentos que ofereciam aos celebrantes. As mulheres das elites passeavam pelas ruas, vestindo seus melhores trajes, inadequados para a ocasião, segundo o viajante. A cerimônia pública se constituía como palco para ostentar riqueza e poder a partir da aparência. Nos espaços privilegiados das elites, principalmente nos bailes nos salões ou nas residências, a comemoração incluía danças, apresentações musicais, jogos e ceia regada a bebidas e com farta degustação de doces.

\title{
Considerações finais
}

O olhar dos viajantes sobre as mulheres, transformado em texto direcionado a seu público - as sociedades envolvidas com os desafios da modernidade - , permitiu que a literatura de viagem, ao mesmo tempo, abrisse espaço para a construção, por oposição, de um discurso sobre a alteridade e sobre o papel do europeu na absorção das sociedades americanas.

A condição de estrangeiro não garantiu um olhar capaz de isenção e, por este motivo, muitas vezes, os viajantes foram responsáveis por uma série de estereótipos que marcaram a imagem das mulheres brasileiras, tais como a sensualidade, docilidade e submissão, dentre outros. Ao que parece, os discursos oitocentistas construíram-se em

17 A Europa passava pela segunda revolução industrial. E profundas transformações no campo social, político e tecnológico. 
um espaço de auto-reflexão filosófica de caráter estreito, paralelamente à sua substituição por certezas respaldadas por saberes científicos, partindo da hipótese da excelência da sua civilização e da confirmação de seus pressupostos de um modelo que seria realmente factível e propriamente humano.

Ainda assim, a experiência da viagem e da literatura de viagem se apresentam como espaço privilegiado para recolher pistas que nos auxiliem a compor o quadro comportamental das mulheres na sociedade portoalegrense na Província do Rio Grande do Sul.

Tratando-se da figura da mulher, personagem lacunar na historiografia do período, sua presença foi percebida nas mais diferentes atividades e de uma forma não tão passiva como registram visões tradicionais, trabalhando, negociando, montando cavalos, sorrindo e, caso específico deste trabalho, divertindo-se, vivenciando tempo fugaz de emancipação, nas brechas da condição de reclusão em que viviam.

Não defendemos a ideia da existência de um quadro emancipatório feminino na província rio-grandense, mas as observações dos viajantes permitem, considerando os filtros existentes, formularmos uma idéia menos homogênea de nossos cotidianos passados e compreendermos os complexos sistemas de relações que se formavam na sociedade portoalegrense, onde, por vezes, as narrativas compuseram um perfil distante da imagem perenizada pela historiografia da "prenda" frágil e caseira.

\section{Referências}

AVÉ-LALLEMANT, Robert. Viagem pela Província do Rio Grande do Sul: 1858. São Paulo: Itatiaia, 1980.

AZAMBUJA, Cristine Splenger. Os dois lados da janela: o público e o privado das mulheres porto-alegrenses entre 1774 e 1887. Dissertação de Mestrado apresentada ao Programa de Pós-Graduação em História da Unisinos, 2006.

BANDEIRA, Lourdes Maria; OLIVEIRA, Eleonora M. Trajetória da produção acadêmica sobre as relações de gênero no grupo de trabalho Mulher e política. In: Ciências Sociais, São Paulo: ANPOCS/Vértice, 1991.

BATISTA, Eduardo Luis A. O. Literatura de viagem e tradução literária como criadores de imagens culturais. Tradução e Comunicação, nº 18, Ano 2009. Disponível em http://sare.unianhanguera.edu.br/index.php/rtcom/article/viewFile/1019/652 Acesso em 20/8/2010.

BENJAMIN, W. O Narrador. In: Textos Escolhidos. São Paulo: Câmara Brasileira do Livro, 1983.

BORGES FORTES, João. Santas Mães. Arquivo Aurélio Porto. Lata 27 - $\mathrm{n}^{\circ} 2$ - cópia datilografada [fl. 1r]. Revista do IHGRGS, Porto Alegre, 1998, $\mathrm{n}^{\circ}$ 133, 147-153.

BURKE, Peter. A escrita da História: novas perspectivas. São Paulo: UNESP, 1992. BURKE, Peter. Variedades de História Cultural. Rio de Janeiro: Civilização Brasileira, 2000. CARDOSO, Sérgio. O olhar dos viajantes. In: NOVAES, Adauto (org.). O olhar. São Paulo: Cia das Letras, 1989.

DA MATTA, R. Carnavais, malandros e heróis. Rio de Janeiro: Graal, 1980. DEL PRIORE, M. Festas e utopias no Brasil colonial. São Paulo: Brasiliense, 1994. DURKHEIM, E. As formas elementares da vida religiosa. São Paulo: Martins Fontes, 2000. DUVIGNAND, J. Fêtes et civilisations. Paris: Weber, 1973.

ELIAS, Norbert. O processo civilizador: uma história dos costumes. Rio de Janeiro: Zahar, 1990. 


\section{Conexão Letras}

FRANZEN, Beatriz Vasconcelos. Mulheres açorianas na formação do Rio Grande do Sul. In: ARQUIPÉLAGO.HISTÓRIA, 2a série, VIII (2004) p.11-19. Disponível em: http://repositorio.uac.pt/bitstream/10400.3/394/1/Beatriz_Franzen_p11-19.pdf. Acessado em 5/6/2010.

GREENBLATT, Stephen. Possessões maravilhosas - o deslumbramento do novo mundo. São Paulo: EDUSP, 1996.

GUTFREIND, Ieda. A Historiografia Rio-Grandense. Porto Alegre: Ed. Universidade/ UFRGS, 1992.

HALBWACHS, Maurice. A memória coletiva. São Paulo: Vértice, 1990.

ISAMBERT, F. Le sens du sacré. Paris: Minuit, 1982.

ITANI, Alice. Festas e calendários. São Paulo: UNESP, 2003.

LEPETIT, Bernard. Por uma nova História Urbana. São Paulo: Ed. da USP, 2001.

Estou à disposição para quaisquer outras correções.

MORAES FILHO, Melo. Festas e tradições populares no Brasil. São Paulo EDUSP/ Itatiaia, 1979.

NOAL FILHO, Valter Antonio; FRANCO, Sérgio da Costa. Os Viajantes Olham Porto Alegre: 1754-1890. Santa Maria: Anaterra, 2004. (a)

. Os Viajantes Olham Porto Alegfre: 1890-1941. Santa Maria: Anaterra, 2004. (b)

REICHEL, Heloisa Jochims. A mulher rio-platense na visão dos viajantes: um sujeito histórico. In: Anais Eletrônicos do IV Encontro da ANPHLAC, Salvador, 2000. Disponível em: http://www.anphlac.org/periodicos/anais/encontro4/reichel.pdf, acessado em 5/6/2010.

SOIHET, Rachel. A sensualidade em festa: representações do corpo feminino nas festas populares no Rio de janeiro da virada dos séculos XIX a XX. In: Diálogos Latinoamericanos, n. 002, 2000, p. 92-114. Disponível em http://redalyc.uamex.mx/ pdf/162/16200208.pdf Acesso em 20/6/2010.

SOIHET, Rachel. História das mulheres e relações de gênero: debatendo algumas questões. Disponível em: http://www.comciencia.br/reportagens/mulheres/16.shtml, acessado em 12/12/ 2006.

SOIHET, Rachel; PEDRO, Joana Maria. A emergência da pesquisa da História das Mulheres e das Reações de Gênero. In: Revista Brasileira de História. São Paulo, v. 27, $n^{\circ}$ 54, p. 281-300, 2007.

THOMPSON, E. P. Costumes em comum. Estudos sobre a cultura popular tradicional. São Paulo: Companhia das Letras, 1998.

WIEDERSPAHN, Henrique Oscar. Das guerras Cisplatinas às guerras contra Rosas e contra o Paraguai. In: Enciclopédia Rio-grandense. Canoas: Editora Regional, 1956. 